\title{
Studies for the Virtual Reconstruction of the Terme del Foro of Cumae
}

\author{
Riccardo Florio \\ Raffaele Catuogno \\ Teresa Della Corte \\ Veronica Marino
}

Abstract

Resuming the cognitive process started in a previous study of integrated survey and interpretation of the remains of the Terme del Foro of Cumae in the Parco Archeologico dei Campi Flegrei, with this contribution, we intend to set up, a methodology to deepen the investigation already carried out on the current consistencies of the thermal system that, through the preparation of a suitable neural network managed by Al processes and structured for the systematic analysis of differences, is able to formulate reconstructive hypotheses with scientific authority.

By integrating the possibilities of traditional methods of investigation on architectural and archaeological heritage, it will be possible not only to highlight what can be directly observed in situ, but also to enhance traces that are not immediately decodifiable and even latent, automatically emerging as the results of comparative investigations on large amounts of data whose logical structure will be clearly traceable along artificial neural 'meshes' similar to human cognitive processes.

Keywords

cognitive networks, comparative analysis, wall textures, roman baths, Cumae.

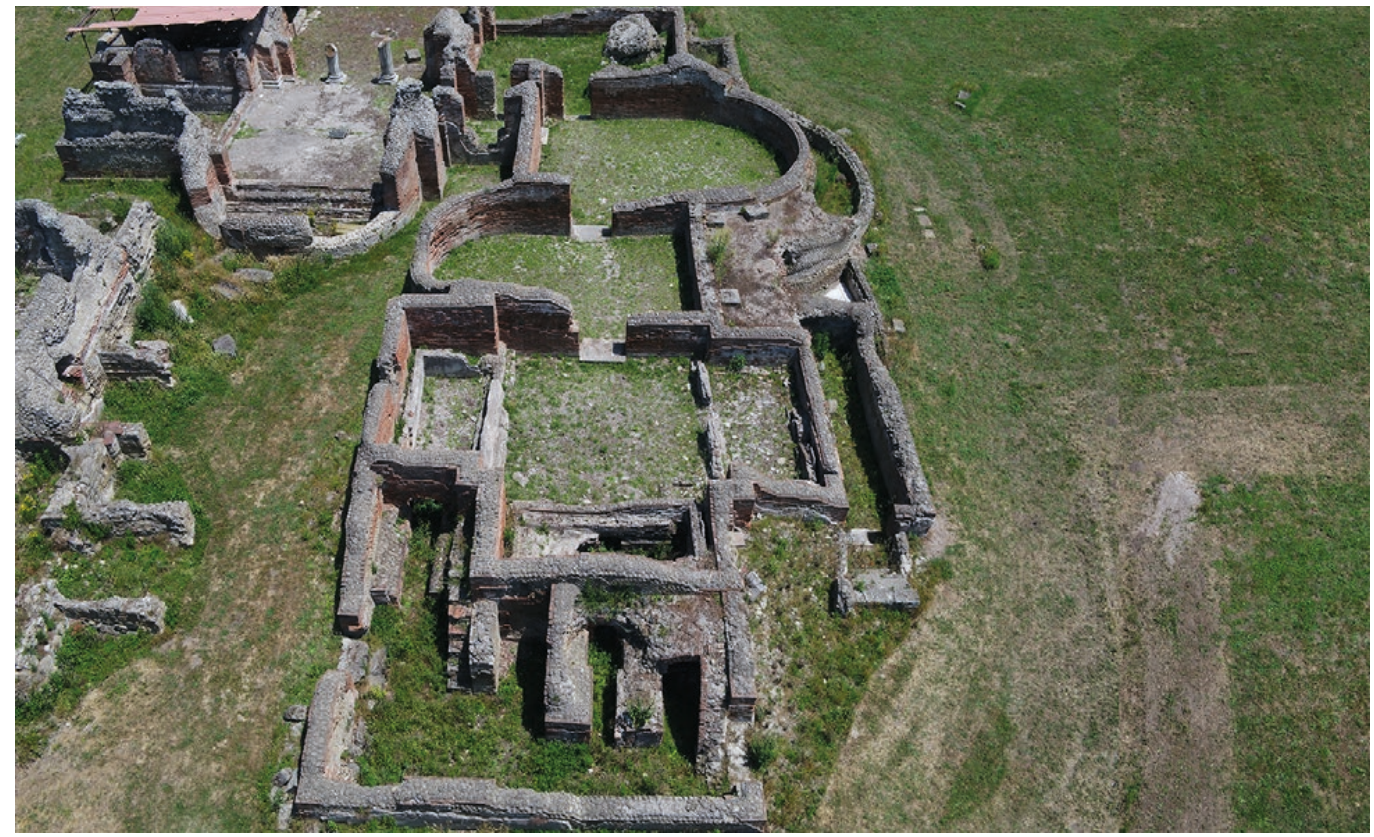




\section{Methodological Reflections}

With reference to the cognitive process initiated in a previous study that, starting from integrated survey operations, has produced interpretative results for the archaeological site of the Terme del Foro of Cumae [Florio et al., 2020], it was intended to identify a research methodology that, activating processes of Artificial Intelligence (AI), makes it possible to found reconstructive hypotheses for the Cumaean thermal system on the basis of scientifically validated processes oriented to a deeper and shared knowledge. The aim is to obtain, through the image-based systems and digital visualization technologies, an expanded 'cultural accessibility' for our architectural and archaeological heritage, which allows not only to visit the remains - in situ and/or remotely - and perceive the original consistency with the help of Virtual Reality (VR) and Augmented Reality (AR), already adopted in various important interventions of valorization of sites and museums, but above all to document and communicate in a transparent and accessible way the iter and the 'intellectual integrity' of the research process, allowing users and other scholars to retrace and critically evaluate, contextually to the story of the stratifications in the various phases of life of the sites, the methodological criteria that have guided the reconstructive hypothesis. The use of Information Communication Technologies (ICT) - and the consequent, increasingly refined, possibility of creating forms of digital memory capable of associating a very high density of data to the assets of interest (directly retrievable data overlaid on previous documentation) - is now fundamental in the field of virtual archaeology. Applying to these large masses of information the comparative processes typical of $\mathrm{Al}$, one obtains results whose generative process, clearly traceable along 'meshes' of artificial neural networks similar to human cognitive processes, is accessible and therefore open to refinement or possible corrections. These logical structures, grafting a propulsive field of support for established interpretive tools, lend themselves formidably to the dialectic of continuous informational feed-back necessary for a sustainable predictive formulation of the original sites. By abstracting the multiplicity and continuity of reality, they integrate the methods of traditional architectural-archaeological documentation, allowing to manage and monitor, through representation, not only the virtual reconstructions (and with them the surviving consistencies in situ) but the same process of convergence that recomposes the ancient remains, thus bringing scientific authority to digital visualizations, constitutively exposed to the risk of overestimation (unconditional appeal of contemporary media) if not even vacuity for lack of transparency or hyperrealism.

\section{The Study Site and the Neural Networks}

The valuable remains of the Terme del Foro were brought to light during an excavation campaign in 1952 at the ancient city of Cuma. The study site is located in the so-called 'città bassa', "a quarter of Samnite and Roman times that was developed in the flat area that stretches to the east between the acropolis and the slopes that rise towards the Arco Felice" [Maiuri 1934, p. I43]. With respect to the original configuration that rose to north of the Temple Capitolium of the Roman city, the Maiuri found in 1958 the rests "of a grandiose thermal building of the I and II century of the empire with vast environments in which the rooms of a calidarium with the apparatus of the prefurnio are recognizable" [lvi, p. I44].

Among the most indicative factors to guide the dating of the first plant of the Terme del Foro of Cumae archaeologists have identified the correspondence of the planimetric type of the spa complex with the so-called half-axial ring type, widely found in Roman sites of the Hadrianic period. It is clearly legible in situ, in the semi-symmetrical articulation of the environments evidenced by a main scenographic axis which, from the entrance vestibule, crosses the intercolumn of the remains (bases and part of the shafts) of two monumental columns in marble extending towards the concavity of the semicircular pool of the frigidarium and by a parallel secondary axis along which the concatenation of the warm spaces (tepidarium, sudatorium, calidarium, praefurnia) is arranged (fig. I).

In support of this hypothesis for the dating is the evidence, in the surviving structures, of masonry and flooring techniques, and of materials, typical of the Phlegrean territorial 
Fig. I. Orthographic horizontal section from TLS and orthographic horizontal projection from SAPR of the thermal complex with indication of the origin functional destination of the various rooms.
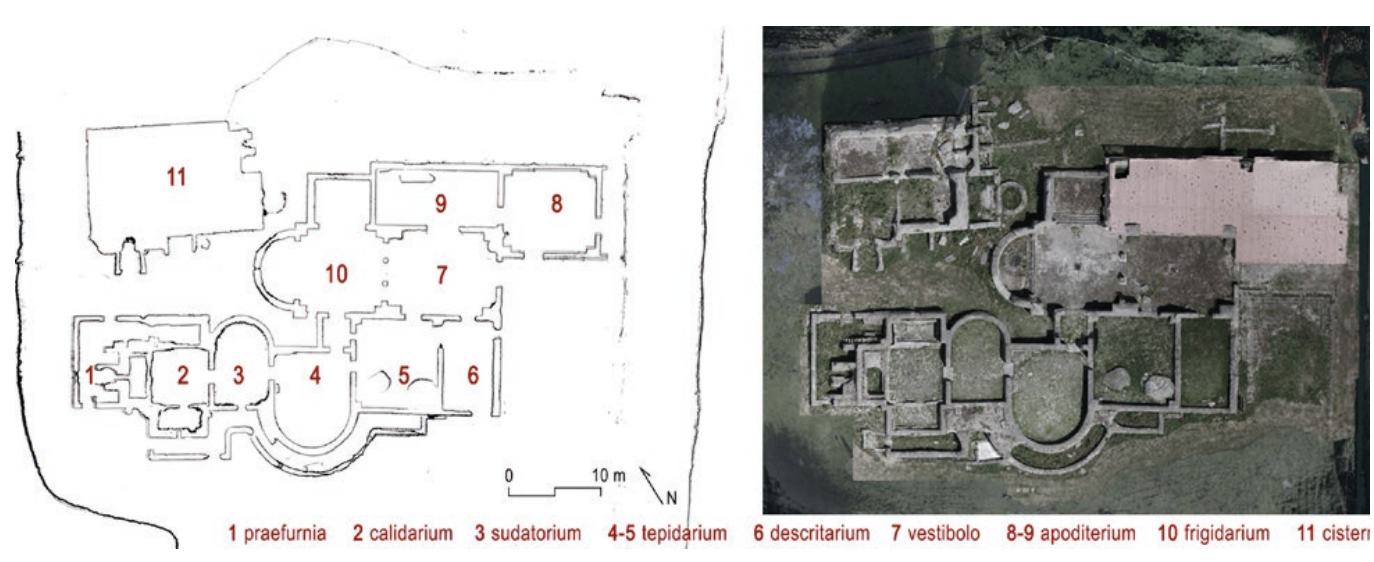

context in the above-mentioned period: at a first reading we find with prevalence the opus latericium in bessales for the internal curtains of the warm rooms and the opus reticulatum with latericium reinforcements for the external curtains and for the interiors of the remaining rooms, and also flooring remains in tessellated with a white background. With the aim of intercepting the construction phases of the thermal site to recompose reliably the original consistencies of buildings and wall fragments, integrating the results of archaeological studies conducted, the in-depth study - which is still in progress, at the moment involving the preliminary phase of the research and preceding what will be the application and implementation phase - is aimed at tracing in the remains of the ancient complex, which are considerably lacunose and compromised (also by having been brought to light through a simple excavation operation rather than through stratigraphic excavation), those variations and anomalies that can suggest the stratified structures in the various ages. Through the predisposition of a neural network managed by Al processes and structured for the systematic analysis of the differences - dimensional and density differences of ashlars and mortars, discontinuity of material and facing, texture anomalies (masonry or floor tesserae), etc. - in the subsequent research development phase, it will be possible not only to highlight what is directly related to the stratified structures, but also to the anomalies of the stratified structures. - it will be possible not only to highlight what can be directly observed in situ but, by widening in a formidable way the possibilities of traditional methods of investigation and observing the considerable practical advantages offered by the speed of comparison and deduction of the new Al systems, to systematize and enhance aspects and properties not immediately decodifiable and traces even the most latent, such as those material and/or color, automatically emerging as the results of ordered comparative investigations, bringing scientific basis to the hypothesis on the chronological order, up to recompose reliably, and according to various degrees of plausibility because of the convergence of results, the original configurations of the artifacts.

\section{Studies for the Cognitive Analysis of the Terme del Foro}

Confirming the indispensability of a hermeneutic action at the base of the hypothesis of virtual reconstruction of the sites, the innovative applications of Al project the methods and the consolidated practices of investigation in the field of ICT and of the complex analysis of large amounts of data, where the experience and the methodological rigor of traditional research are capitalized in favor not only of a high efficiency and speed of results - the automatic recognition of apparently insignificant elements, such as fragments or minimal traces of events, becomes an extraordinary tool to reveal the dating and recomposition - but above all the possibility of making the 'story' and the logical structure of the research accessible simply through the reading (graphical) of the system of relations established by the neural networks. Already in the field of the consolidated methods, the interpretative accuracy of the stratigraphic method is precious for the knowledge of the sites: integrating itself to the phase of excavation, the method contemplates the drawing up of plans of interface for ev- 
Fig. 2. Exemplificative framework of the variations and/or anomalies able to suggest the stratified structures in the various epochs. ery recognizable stratigraphic unit (overlays), deducing stratigraphic diagrams (matrix) that condense icastically the data found. Other analytical methods, applied in diachronic phase with respect to the excavation, have been using for years deductive processes based on logics structured by input data, 'weighted' relations, levels of investigation, predictive output. Through the mensiochronology, moreover, the multiple input parameters do not acquire meaning in themselves: size and shape of the tesserae or ashlars, their number per unit area, irregularity factors, etc., are considered contextually, as parts of a comparative structure able to develop trend lines for the attribution of chronological bands to the buildings of antiquity. Artificial intelligence algorithms, genetically inclined to the investigation of complexity, allow us to greatly implement these deductive processes, programming operations (of analysis and synthesis) capable of investigating millions of data in all their informative potential (big data systems) in order to have new answers to questions about the past. The cognitive analysis on the Terme del Foro will have to be set up by providing the system with the highest number of data - from those that can be taken in situ, by means of TLS and photogram-

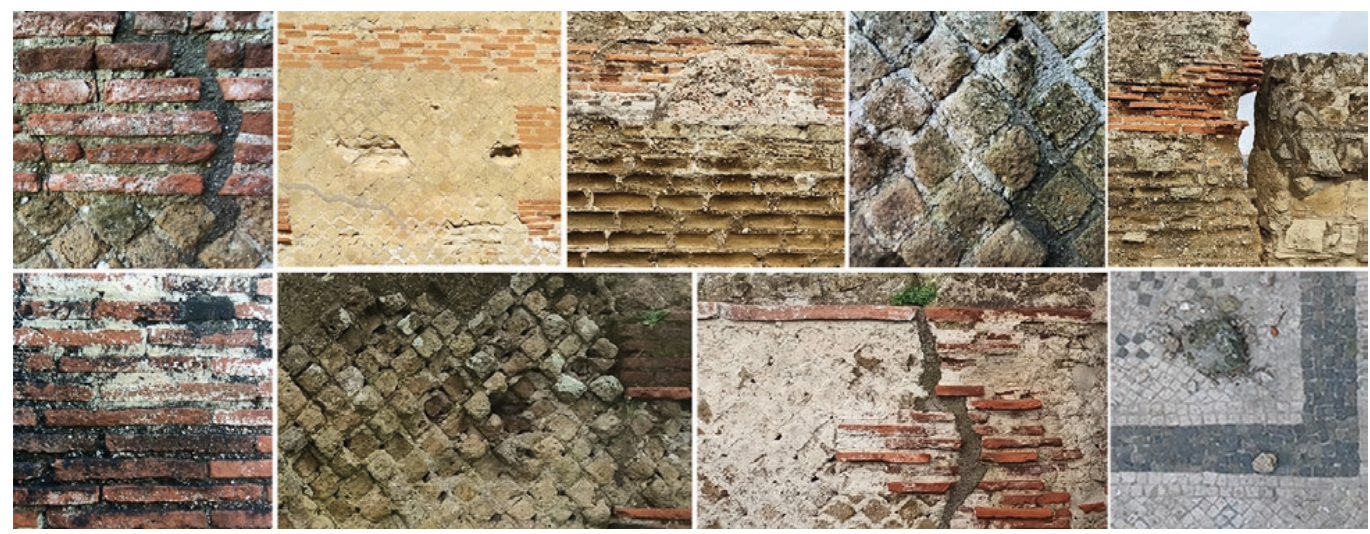

metry (orthophotos, photographs, photomosaics, photogrammetries) to those that can be deduced from previous studies or documentation (Roman building systems and those of the following ages, documentation related to wall textures, to the materials used, and building appropriate image-based algorithms capable of recognizing the different periods and reaching, on the basis of thousands of comparison operations (identification of differences, and similarities, between a large number of images, photographs, drawings, historical data) to possible original configurations (fig. 2). If, for example,the experiment were to be applied to the current configuration of the wall textures of the calidarium - the last in the sequence of the hot rooms and one of the most affected by wall anomalies and by interventions of reconstruction and/or transformation - the data to be entered would concern the reticulatum and the latericium of the mixed work detectable in the external curtain, the differences between the pieces analyzed by type of ashlars (cubilia, bessales), their ratio with respect to the average size $(7 \times 7 \mathrm{~cm}$, for cubilia; from 23 to $28 \mathrm{~cm}$ of side, for the bessales), the variations in the composition of the mortar (with or without volcanic inclusions), the chromatic tonalities of the bricks and their deviation from the uniform orange-pink color, etc. It will also be necessary to document and insert images of the inserts in opus vittata, of the mixed opus vittata and brickwork, of the brickwork compensations, of different color and workmanship, probably relative to a phase subsequent to the first installation and to obtain data on the cores between the two curtains (prevalently in opus caementicium), investigating the summit wall crests opened by the gradual and progressive deterioration of the thermal remains. Above all, it will be necessary to design the neural network, setting the layers (depth of the network), the number of different features that the network examines at each level (width of the layer), the connections between the data and the layers (weight of the relationships) and opting for a 'convolutional' structure (same pattern of connections between layers) rather than a 'recurrent' one (possibility of 'feedback' between non-adjacent layers) [Hartnett 20l9] (fig. 3). 
Fig. 3. Simulative hypothesis of the structure of a neural network for the extraction of discriminating features for the original configuration of masonry in opus reticulatum The process assigns differentia wess to the connections, distinguishing the differential relevance of the nodes ('full' and 'empty' nodes) for the outcomes; the system also provides feedback connections, filtering out noise and retainin only the most relevant features.

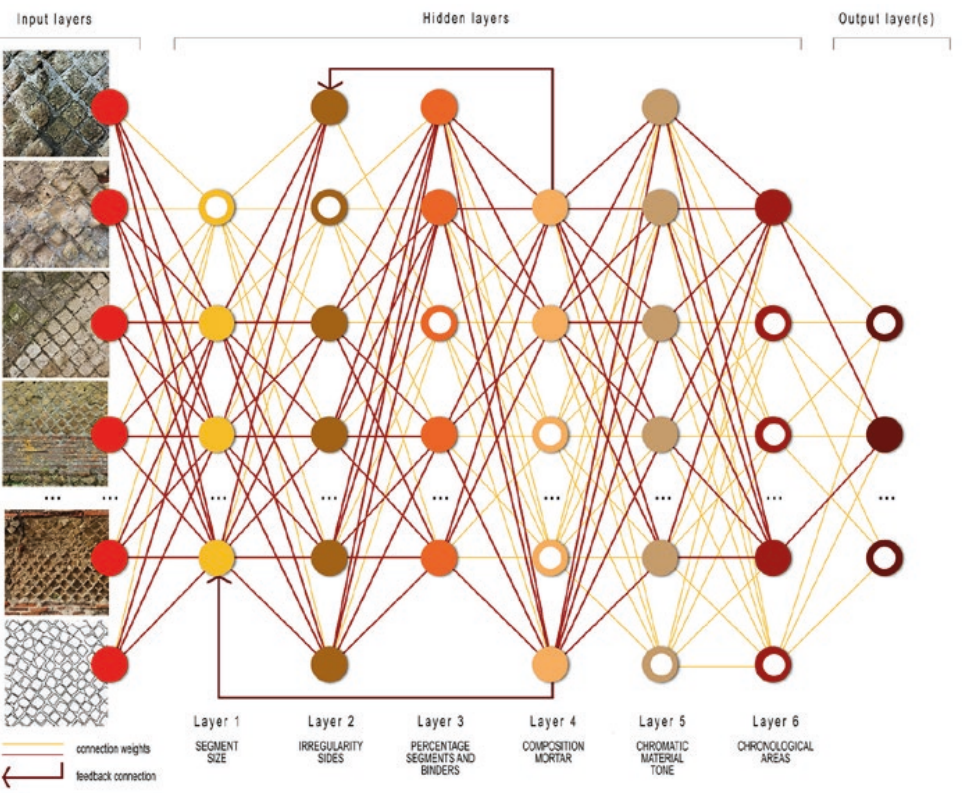

\section{Conclusions}

The results of the elaborative operations activated by the neural network in adoption, as well as being archived within the procedural application itself - making permanently available for consultation both the data and the results of the research, as well as the related generative and cognitive process - may be valuable support for a subsequent three-dimensional modeling of the study site. Consistently with the guidelines for a mature virtual archaeology, inspired by criteria analogous to the modern principles of architectural-archaeological restoration [Brusaporci, Trizio 2013, pp. 55-68], the knowledge of the thermal complex, represented in wireframe compositing in order to distinguish the reconstructed parts and allow progressive interpretative updates, will be made accessible and permanently monitored by users in situ and/or remotely, through the adoption of web-based and open source technologies; moreover the applications of AR and the interactive modalities of the digital visualization will be able to associate to the 3D model multiple information and to reveal the relationships between the existing and the reconstructed, favoring the comprehensibility of the ruins.

\section{References}

Brusaporci Stefano, Trizio llaria (2013). La "Carta di Londra" e il patrimonio architettonico: riflessioni circa una possibile implementazione. In SCIRES, 3 (2), pp. 55-68.

Caputo Paolo (1994). Cuma. Terme del Foro. Saggi di scavo. In BA, I I- I2, pp. I73- I 75.

Florio Riccardo, Catuogno Raffaele, Della Corte Teresa, Marino Veronica, Dilauro Valeria (2020). Architettura archeologia per il rilievo integrato, il caso esemplare di Cuma: le Terme del Foro. In AA.W. (eds.). Connettere Connecting un disegno per annodare e tessere, drawing for weaving relationships. Atti Convegno UID. Milano: FrancoAngeli, pp. 2 I 82-2203.

Gabellone Francesco (2012). La trasparenza scientifica in archeologia virtuale. In SCIRES, 2, pp. 99-I23.

Hartnett Kevin (2019). Per una teoria generale delle reti neurali. In I quaderni de Le Scienze, 4.

Maiuri Amedeo (1934). I Campi Flegrei Dal sepolcro di Virgilio all'Antro di Cuma. Roma: Istituto Poligrafico e Zecca dello Stato.

Nielsen Inge (1990). Thermae et balnea, Architecture and cultural History of Roman Public Baths, I-II, Aahrus: Aarhus.

Authors

Riccardo Florio, Dept. of Architecture, University of Naples, riccardo.florio@unina.it

Raffaele Catuogno, Dept. of Architecture, University of Naples, raffaele.catuogno@unina.it

Teresa Della Corte, Dept. of Architecture, University of Naples, teresa.dellacorte@unina.it

Veronica Marino, Dept. of Architecture, University of Naples, veronica.marino@unina.it 
